\section{Newton as alchemist}

\section{A. Rupert Hall}

The Foundations of Newton's Alchemy. By B. J. T. Dobbs Pp. $x^{+300 . ~(C a m-~}$ bridge University; Cambridge, 1976.) $£ 10.50$.

EVER since David Brewster published his Victorian biography of Isaac Newton 120 years ago it has been known that Newton devoted much time to chemical experiments and alchemical authors; indeed, Brewster, while faithfully noting his hero's purchases of chemicals, apparatus and Ashmole's Theatrum Chemicum, lamented his waste of time on Ripley, Flamel, Starkey and the rest. Moreover, Newton's interest in these matters has long been evident from his correspondence. The dispersal of the great mass of Newton's private papers in 1936 simply made openly available a mass of material that had been formerly known but largely inaccessible, and which in any case had not been regarded as very important to those who were more interested in Newton as the founder of mathematical physics than as a man of his own age.

The mood has changed, so that during the past thirty years many have pursued Newton the whole man, rather than the author of Principia, Opticks and some mathematical treatises. 'Freudian' analysis has laid bare the mechanics of his personality, and he has been portrayed as theologian, historian, Mint Master, magus, and most recently as alchemist. How much light all this knowledge derived from deep reading and wide scholarship actually throws on Newton's role in the history of mechanics or optics is still an undecided question. The first attempt, by David Castillejo, to discern a unity in all Newton's work has remained unprinted (although copies are on deposit in certain libraries). In her new study of the earlier phase of Newton's interest in chemical topics Mrs Dobbs, after setting out the background that Newton inherited, investigates the kind of information about the nature of metals that Newton was looking for in his alchemical authors, and relates this to his own experimental endeavours. Finally, like Mr Castillejo (but more precisely), she explores the relations between alchemy, theory of matter and the concept of gravitation.

There is a difficulty in this aspect of Newton's work-for it was certainly a

Illustration shows the 'greene lyon' devouring vivifying celestial influences, symbolised by the Sun, and emitting a vivified mercury, the living or 'actuated' character of which is symbolised by blood. serious enough activity to be judged work-which is encountered in studying Robert Boyle and others too. Newton actually published in his lifetime certain perfectly rational views about chemical properties and the nature of matter (which were not without influence on the development of chemistry as a science). We also possess factual and fairly straightforward accounts of experiments that he made on such and such days written in his own hand. We have again personal and authentic expressions of interest as in his letters to Aston (as early as 1669) and to Locke about Boyle's supposed incalescence of gold with mercury (August, 1692). And in his London years, later still, Newton kept up an acquaintance with the alchemist William Yarworth. Finally, there is the known extent of his own alchemical library and of his voluminous extracts from alchemical authors, by no means excluding those of the esoteric sort. What is largely (but not, it seems, absolutely) absent is any comment, explanation, or reworking of this last material from Newton's own pen. His purposes, his intentions, his possible ambitions in collecting and studying it, have to be for the most part inferred.

As is evident from Newton's published chemistry, and from the experimental records first analysed by my wife and myself many years ago, Newton's mind in all this worked at a rational, factual, indeed quantitative, level. In this respect Newton's pyrotechnical work shows no difference of principle from his work in optics. If this were not true it is impossible to understand how Query 31 or De natura acidorum could have been written. Much as we proposed nearly twenty years ago, Mrs Dobbs writes of Newton's translating alchemical processes into chemical terms which he could then subject to trial in the laboratory. If he plunged for enlightenment into the "most esoteric and mysterious productions of the alchemists", he sought their meaning by 'rational analysis', and experimented

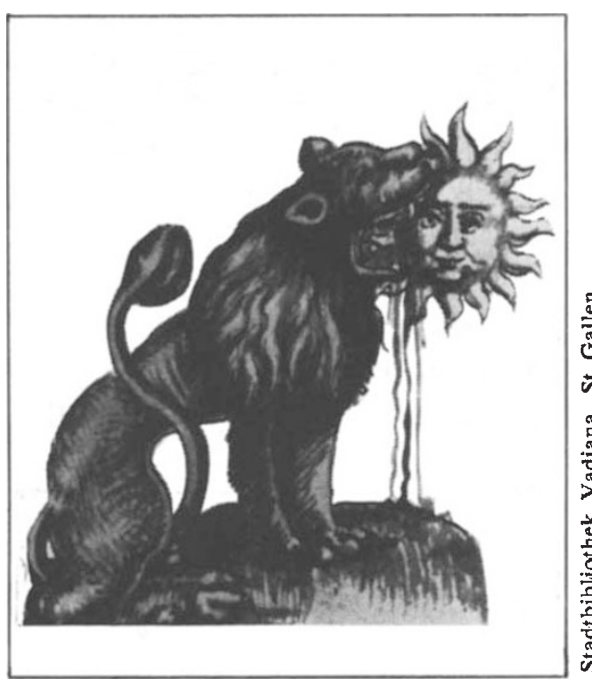

methodically, almost ploddingly (pp168 and 175).

In Boyle's and Newton's day it was of course perfectly rational to suppose that metals might be compound bodies and capable of chemical modification. According to Mrs Dobbs, in a manuscript of his own composition headed Clavis (Key), Newton wrote out a detailed account of a process for preparing "a mercury dissolving all metals, particularly gold". (Its humourless author noted that "one philosophical sign will appear to you: in the very making of the mercury there is a great stink".) Such solution was preliminary to the complete mastery of metals. Like Boyle, the writer of the Clavis saw gold apparently fermenting and changing colour in this menstruum.

What is rather at stake is the question of Newton's commitment to the alchemists' ideas. Did their writings not merely contain hidden clues to actual procedures which could be verified or falsified in the fire, but a profound esoteric insight into the workings of nature? Here (as also in Mrs Dobbs' conjectural "school" of alchemy in Cambridge, whose leading activists were Isaac Barrow and Henry More, with Newton as their neophyte) it is less easy to accord with her views. It is true that Newton in Opticks and in the discussion of comets in the Principia hints at the transformation of a cosmic 'spirit' into water and so (as Boyle thought he had proved) into earth; such a progressive coalescence of the fundamental particles of matter (neither fermions nor bosons!) was not forbidden by contemporary theory, and had indeed been invoked by Descartes.

There are other ways too in which, as Mrs Dobbs rightly points out, Newton's faith in the "analogy of nature" led him into strange, or at least empirically unjustified speculations. But it seems needless to derive the concept of gravitational "attraction" (which Newton after all declared did not need to be an attraction and was certainly not inherent in matter) from alchemical origins, and extreme to affirm that "in a sense the whole of his career after 1675 may be seen as one long attempt to integrate alchemy and the mechancial philosophy" (p230). Are the mathematical papers in Dr Whiteside's eight volumes equally to be seen as of no significance in Newton's intellectual development?

Nevertheless, even the reader who may feel some reluctance to substitute Caput Mortuum for Caput Draconis, and some suspicion of any single key to the secret $\varpi$ of Newton's greatness (many have been offered), must find his understanding of Newton broadened and stabilised by Mrs Dobbs' explorations of the more obscure recesses of his mind.

A. Rupert Hall is Professor of the History of Science and Technology at Imperial College, London, UK. 